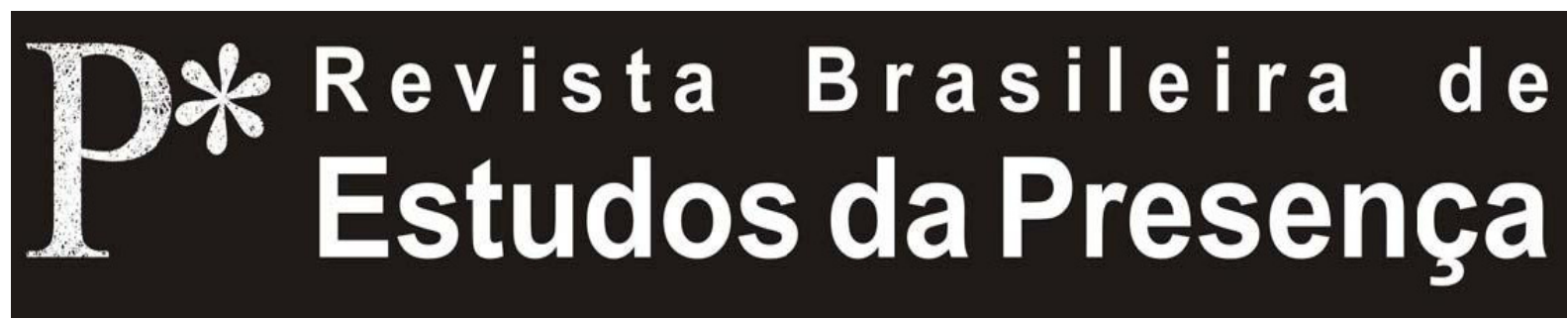

DOI - http://dx.doi.org/10.1590/2237-266022922

ISSN 2237-2660

\title{
Pérolas de Sabedoria nas Noites de Sexta-Feira
}

Thomas Leabhart

Pomona College - PC, Claremont, Estados Unidos da América

RESUMO - Pérolas de Sabedoria nas Noites de Sexta-Feira ${ }^{1}$ - Este texto testemunha a pedagogia de Etienne Decroux e, em especial, as aulas dadas no início da década de 1970 no porão azul de sua casa na periferia de Paris. Apresentam-se as peculiaridades dos ensinamentos de mímica com ênfase nas lições de improvisação teatral dadas às sextas-feiras à noite. Discutem-se as incongruências e a potência do pensamento e do legado de Decroux para o teatro contemporâneo, sobretudo para a pedagogia do ator.

Palavras-chave: Etienne Decroux. Improvisação Teatral. Pedagogia do Ator. Mimo Corpóreo. Ator.

ABSTRACT - Friday Night Pearls of Wisdom - This text testifies to the pedagogy of Etienne Decroux and, in particular, to his lessons in the early 1970s in the blue basement of his house on the outskirts of Paris. The author presents peculiarities of the teaching of mime with emphasis on Decroux's theatrical improvisation lessons taught every Friday night, and discusses the ambiguities and the power of Decroux's thought and contributions to contemporary theatre, especially to acting pedagogy.

Keywords: Etienne Decroux. Theatrical Improvisation. Acting Pedagogy. Corporeal Mime. Actor.

RÉSUMÉ - Perles de Sagesse dans les Nuits du Vendredi - Ce texte offre un témoignage de la pédagogie d'Etienne Decroux et, en particulier, des cours donnés au début des années 1970 dans la cave bleue de sa maison à la périphérie de Paris. Il présente les particularités de l'enseignement du mime, en mettant l'accent sur les leçons d'improvisation théâtrale données les vendredis soirs. Il aborde les incongruités et la puissance de la pensée et de l'héritage de Decroux pour le théâtre contemporain, notamment en ce qui concerne la pédagogie de l'acteur. Mots-clés: Etienne Decroux. Improvisation Théâtrale. Pédagogie de l'Acteur. Mime Corporel. Acteur. 
Os meus anos na escola de Etienne Decroux, de 1968 a 1972, incluíram cerca de 200 sextas-feiras ansiosamente antecipadas e ferozmente temidas. Além das habituais aulas de técnica das manhãs e fins de tarde, nas sextas-feiras à noite todos os estudantes compareciam ao que Monsieur gostava de chamar de séance de vendredi. O evento era dividido em duas partes: na primeira hora, a palestra de Decroux - na realidade respostas a questões e uma explanação filosófica sobre a mímica corporal ${ }^{2}$; em seguida, durante aproximadamente uma hora, uma oportunidade para os estudantes apresentarem improvisações solo, em duplas ou grupos sobre os temas propostos pelo nosso professor.

No decorrer dessa aula, nós usávamos casacos por cima de nossas roupas de prática (inverno ou verão, pois o porão era frio) e sentávamos em banquetas de lona dispostas ao redor do perímetro de um lado do estúdio. Todos nós compreendíamos a importância dessas reuniões e, escorados nas paredes úmidas do porão, mantínhamos blocos de anotações ou pequenos gravadores para tentar documentá-las da melhor forma possível ${ }^{3}$. Apesar do tom formal, o evento também tinha toques absurdamente deliciosos de humor, pois Decroux frequentemente ridicularizava a si próprio, a arte que ele gastou sessenta anos desenvolvendo e ensinando, e seu humilde estúdio ("Nunca esqueçam que os primeiros cristãos também se encontravam em catacumbas!"). Esse humor, que nos encantava, ajudava a aliviar um pouco a tensão - enquanto escutávamos com parte dos nossos cérebros, outra parte nunca esquecia que dentro de uma hora sentiríamos um prazer e um terror requintados ao improvisar para ele. Se ele gostasse da improvisação, a nossa coragem se mantinha por mais uma semana de trabalho; se ele não gostasse, a espera por uma nova oportunidade de se redimir era longa.

Monsieur lecionava, ou, mais corretamente, respondia exaustivamente às perguntas feitas pelos estudantes, sentado em uma cadeira branca atrás de uma pequena mesa de madeira envernizada com abas rebatíveis trazida da deuxième cave especialmente para a ocasião. Decroux mandou transformar aquela parte inacabada do porão em uma segunda sala de aula 
após 1972. Mas, no meu tempo, esse depósito continha garrafas de vinho empoeiradas, ferramentas de jardim, pequenas tábuas de masonite em formato de mão esticada (usadas pelos estudantes para praticar posições da mão), caules de gerânio, pendurados com as raízes para cima, para resistir aos meses de inverno. O odor pungente daqueles caules nodosos adormecidos desaparecia na primavera quando Madame Decroux os replantava no pequeno pátio do jardim da frente. A metáfora do vaso de gerânio foi introduzida no ensino de Decroux, assim como todas as coisas concretas ao seu redor; nossos braços esticados, não importando a forma desejada, deviam ser fortes o suficiente para carregar vasos de cerâmica cheios de gerânios; para fazer com que o objetivo fosse físico, ele forçava os nossos braços com o peso aproximado dos vasos mencionados acima enquanto gritava "Não se mexa!".

As paredes do porão eram pintadas de azul celeste brilhante e o chão coberto com linóleo azul com linhas brancas; a parede espelhada (e a porta para a deuxième cave) ficava à direita de Decroux enquanto ele lecionava, e a parede externa com pequenas janelas, ao nível do teto que davam para o jardim, ficava à sua esquerda. Decroux sentava-se diretamente atrás de sua mesa, vestindo um pijama de flanela, roupão de banho e chinelas; ele gostava tanto dessa vestimenta a qualquer hora do dia que um amigo meu, que o entrevistou para um jornal, saiu chamando-o de poseur en pyjamas. Para a aula de técnica ele às vezes vestia shorts de algodão preto, camisa preta de mangas compridas e sapatos de couro preto para ginástica, mas ele, também, alegre e confortavelmente, dava aulas de técnica vestindo pijamas.

$\mathrm{O}$ tradutor (a maior parte dos estudantes não era francesa) sentava à sua esquerda parcialmente de frente para Monsieur. Durante o meu cargo naquela posição, eu vestia um roupão de veludo cor de mel, presente de Monsieur e Madame. Essa vestimenta luxuosa substituiu o casaco bastante puído que eu inicialmente vestia nessas ocasiões, mas que os Decroux, sem dúvida, achavam que ia contra a imagem cênica desejada.

Decroux ouvia perguntas sem respondê-las até que ele encontrasse uma que estimulasse sua imaginação. $\mathrm{O}$ prelúdio 
para a resposta consistia de um ruidoso e cerimonioso limpar de garganta após o qual ele puxava das profundezas de um dos bolsos de seu roupão uma bala de mel (ou duas, dando uma ao tradutor), ele abria o papel celofane com um ruído exagerado e jogava o doce na boca, colocando o papel vazio dentro do outro bolso. Assim fortalecido, ele mergulhava na palestra da semana, que frequentemente terminava com o entrelaçamento de respostas para várias daquelas perguntas até então não respondidas e - nós pensávamos - rejeitadas, formuladas no início.

Limpar a garganta e chupar a bala serviam como uma espécie de aquecimento para a sua voz bem colocada, cuja musicalidade, rica em timbres e clareza não foram mal empregadas em nenhum de nós, incluindo os falantes não-nativos de francês. Ele permanece como uma das poucas pessoas que eu conheci que podiam realmente vociferar; e, quando ele o fazia, qualquer coisa (ou qualquer um) a certa distância vibrava. Ele frequentemente comparava a intensidade da articulação necessária na fala com a intensidade da articulação do movimento exigida na mímica corporal. Você deve, ele advertia, articular-se (na fala e no movimento) como se estivesse falando com pessoas surdas.

A maneira de ele falar nessas ocasiões podia ser relaxada e informal, mas à medida que suas emoções aumentavam, ele lembrava frequentemente um orador político. Decroux frequentava grandes reuniões políticas, especialmente na sua juventude, e o seu interesse por discursos políticos o levou primeiro à escola de Jacques Copeau, na qual o estudo do movimento logo tomou o lugar de seu desejo de se livrar de seu accent du faubourg e melhorar sua articulação. Ele gostava da citação: "Para o orador, o Partido está sempre em perigo". Para Decroux, o Partido era a Mímica Corporal e, com frequência, ele discutia assuntos como a mímica ainda não existe ou as enfermidades da mímica. Obcecado pela ideia de que essa arte emergente podia facilmente se extinguir, ele determinou que isso não iria acontecer. Como um feiticeiro, ele nos cativava e nos mantinha com toda a poesia, presença de espírito, paixão e eloquência que ele conseguia reunir acerca de tópicos como 
Mímica Vocal, Mímica e Escultura, Mímica e Filmes de Animação, Mímica e Marionetes, Mímica e Máscaras e Mímica e Música. Ele costumava retornar aos mesmos temas, sempre nos relembrando que ele procedia pela livre associação de ideias, que as suas ideias ainda não estavam completamente estabelecidas sobre essas questões e que as doutrinas - políticas ou artísticas - podiam facilmente tornar-se refúgios para as mentes ociosas. Suas aulas eram improvisações faladas realizadas em resposta às nossas questões do mesmo modo que as nossas improvisações eram realizadas em resposta às suas questões.

Habitualmente, ao final de seus comentários (que geralmente levavam uma hora e pareciam divagar extravagantemente até os últimos momentos, quando ele magicamente amarrava todos aqueles fios soltos e encontrava um caminho triunfante de volta ao tópico da conversa, aparentemente esquecida há um longo tempo), ele sorria timidamente, consciente de que havia realizado um passe de mágica ao eloquentemente citar passagens de suas leituras amplas de poesia francesa, política socialista e arte para sustentar o seu ponto de vista. Como o seu filho salienta, Decroux quase nunca lia livros sobre teatro ou mímica e citava Baudelaire e Hugo mais prontamente do que Stanislavsky ou Brecht. Entretanto, ele mencionava com frequência o seu trabalho com pessoas do teatro cujas ideias ele considerava importante na elaboração da Mímica Corporal, em especial Jacques Copeau, Louis Jouvet e Charles Dullin. Como um autodidata, que implorou à filha de Copeau, Edie (que mais tarde passou a liderar um convento beneditino em Madagascar) que o ensinasse gramática francesa ${ }^{4}$. Ele tinha pouca paciência com os acadêmicos que não possuíam a experiência física que ele tinha e que permaneciam, como ele desdenhosamente os descreveu, sentados. Quando questionado sobre Delsarte, ele admitiu que havia lido as anotações estenografadas de uma de suas palestras mas que não tinha muito interesse por elas já que Delsarte parecia ser uma pessoa sentada falando sobre pessoas em pé, não uma pessoa que, como ele próprio, preferia ficar em pé. Às vezes, no entanto, se ele estivesse cansado ou considerasse as perguntas pouco inspiradoras, a costumeira 
eloquência de Decroux falhava, sua fala perambulava, tomava muitos falsos começos, tornava-se confusa e morria. Nessas raras ocasiões, excepcionalmente vencido pela magnitude de seu empreendimento, ele suspirava alto, lançava as mãos e o olhar para cima e proclamava que, já que havia tanto a dizer, isso era o mesmo que não ter nada a dizer. Invariavelmente, independentemente do sucesso ou fracasso relativos do seu discurso extemporâneo, ele agradecia aos seus ouvintes, observando que eram eles que haviam realizado o trabalho de verdade, já que eles eram obrigados a seguir com dificuldade o caminho por onde ele era facilmente levado pela inspiração.

Em seguida, enquanto alguns estudantes faziam rápidas visitas ao toalete no andar de cima, ele retirava a mesa de madeira, colocava sua cadeira perto das escadas de frente para a parte do estúdio que então viria a ser o palco, talvez limpasse sua garganta e abrisse outra bala de mel (especialmente comprada por Madame na La Vie Claire) e se preparava para o grand finale da séance e da semana: as improvisações. Embora na minha época Decroux desse aula nas manhãs de sábado, essa aula, que ocorria após a grande seriedade das noites de sexta-feira, sempre tinham um clima festivo, quase como um carnaval fora do calendário. Nos sábados nós fazíamos apenas a parte da técnica intitulada de caminhadas.

Visto que a maior parte do ensino de Decroux enfatizava primeiro a técnica e depois a improvisação e a inspiração, na sessão da sexta-feira à noite ele tentava nos mostrar como aquilo que ele chamava de técnica tediosa e árida funcionava na improvisação. Ele fazia isso nos oferecendo um contexto filosófico para o trabalho (a aula) e, então, nos permitindo sentir como essa técnica podia se tornar um recurso para a nossa imaginação, como ela podia funcionar de dentro para fora. Nos seus comentários acerca das improvisações, que ele tentava sem sucesso limitar a poucas observações, ele frequentemente ilustrava como a improvisação podia servir como uma base para a composição de peças teatrais.

Para a parte inspiração primeiro de sua aula, ele pedia que as lâmpadas fluorescentes fossem apagadas e que alguém acendesse dois refletores que ele chamava carinhosamente, 
com um floreio zombeteiro e afetado dos dedos gorduchos, de lumière artistique. Banhados pela fria luz branca desse par de olhos que nunca piscavam, nós realizávamos aquela transição, com mais ou menos sucesso, da teoria para a prática, e o linóleo azul embaixo dos nossos pés tornava-se um céu que nos erguia ou uma espécie de abismo bocejante que nos engolia na derrota. É claro que o olhar fixo de Decroux era o que nos enchia de terror, muito mais do que as opiniões de nossos colegas. Muitas vezes as improvisações solo ou em duplas começavam atrás das cortinas brancas que cobriam a parede oeste do porão. Aguardava-se lá em silêncio pelo momento certo, um momento de vazio apropriado e, então, alguém aparecia, gradualmente ou de repente, pela abertura central atrás das cortinas. Uma mão ou um braço surgia primeiro, às vezes, em câmera lenta, seguido pelo súbito descortinamento do rosto, uma imobilidade e um vagaroso aparecimento do resto do corpo no espaço cênico. Nas improvisações bem sucedidas, não importando o seu tema, o dínamo-ritmo (velocidade, peso e qualidade de movimento) era de suma importância. Nas aulas de técnica, também, movimentos internos, vibratórios, começavam invisivelmente antes do primeiro movimento externamente visível. O corpo começava a cantar por dentro, a tornar-se en-chanté, e continuava a fazê-lo depois que o movimento visível parava ao final da improvisação - Decroux nos lembrava que o motor de um automóvel funciona antes que o automóvel começa a se mover e depois que ele para.

Os temas das improvisações pareciam, ao mesmo tempo, simples e quase impossíveis. Decroux frequentemente escolhia o tema $O$ Pensador (tanto individual quanto em grupo e o qual ele, às vezes, chamava de Meditação); nós manifestávamos com mais ou menos sucesso as atitudes ou ritmos do pensamento - e, talvez em algum momento auspicioso de $O$ Pensador, mudando o vocabulário de movimentos de Homme de Salon para Statuaire Mobile, nos transformávamos em Pensamento Puro. Decroux, às vezes, chamava a improvisação de pensamento-em-grupo de Pausa para o Almoço no Laboratório de Pesquisas. Nós fazíamos, também, um exercício análogo, que ele chamava de Espera, no qual pedia que os 
estudantes manifestassem as cinco qualidades que ele mais comumente associava com a sua mímica corporal: pausa, peso, resistência, hesitação e surpresa. Decroux, muitas vezes, escolhia o Dueto de Amor como um tópico para a improvisação oposto ao $O$ Pensador, e ele calorosamente enaltecia o amor como uma força motora na vida humana; com lágrimas nos olhos ele nos contava como Jesus havia perdoado Maria Madalena porque ela havia amado muito. Nesses contextos, Decroux nos encorajava a explorar as convexidades de um corpo posicionadas próximo às, ou dentro das, concavidades de outros corpos, a explorar o movimento de duas cabeças ou costas coladas uma na outra. Em todas as improvisações, ele insistia que nós desenvolvêssemos relacionamentos entre indivíduos sem olhar: olhava-se através de partes do corpo que não fossem os olhos. Nossos relacionamentos, ele aconselhava, deveriam imitar com sucesso a cumplicidade entre dois cachorrinhos em uma grande lixeira ou a de dois ou mais pensamentos dentro do mesmo cérebro, mas nós nunca devíamos nos relacionar como duas pessoas em uma situação real que exigisse contato visual e verbal. Nós não éramos, Decroux insistia, escravos do realismo.

Decroux reagia aos nossos esforços de transcender, de trabalhar de dentro para fora, de diversas maneiras: escárnio, elogios calorosos, raiva, ternura compassiva. Às vezes, no meio de uma improvisação ele podia ser ouvido respirando alto, no lusco-fusco do porão e dizendo, com um suspiro intenso, "C'est beau, mon petit, continue!" (Está bom, meu pequeno, continue!) Ou então ele interrompia incisivamente com " $\mathrm{C}$ 'est beau, mais c'est pas ça!" (Está bom, mas não é isso!), reconhecendo que a improvisação havia terminado. Frequentemente, nossos esforços eram confrontados com um longo e frio silêncio seguido de um hesitante "Oui, si tu veux" (Sim, que seja) como transição para um longo catálogo de nossos fracassos naquela ocasião em particular - comentários como "Você deve cantar com seus músculos" ou "Você não encontrou o ritmo do pensamento" ou "Não se esforce tanto para ser interessante, apenas seja" ou "Quando você olha diretamente para outro, isso é obsceno" ou "Você cega os olhos do espaço com seus 
gestos brutalmente incisivos". Eu recordo que ele me pediu para "esvaziar o apartamento de modo que Deus possa ir morar láb" e Leonard Pitt recorda uma admoestação semelhante com um colega, desta vez durante uma aula de técnica "Você não deve querer se expressar. Ao contrário, você deve se esvaziar e preencher esse espaço com a alma de Deus". Qualquer coisa que se parecesse minimamente com autoexpressão, Decroux imediatamente combatia com um comentário como "Não se mostre. É indecente mostrar-se!".

Duas deusas míticas reinavam sobre as atividades do porão. A primeira era uma fotografia em preto e branco da Vitória Alada pendurada na parede leste perto das escadas. Decroux, sempre aprendendo com a escultura, gostava do movimento de avanço dessa estátua, do redemoinho aerodinâmico do tecido repuxado para trás contra a figura que se lançava heroicamente para a frente. A segunda deusa era Madame de Billy, que frequentava as aulas de sexta-feira à noite com certa regularidade, uma mulher de certa idade e tamanho, geralmente vestida de preto com um colar duplo de pérolas grandes e perfeitas. Numa foto de 1967, ela me parece agora muito mais jovem do que ela então me parecia, nos anos de 1968 a 1972. Quando ela chegava de táxi vinda de seu apartamento no décimo sexto arrondissement, Monsieur e Madame a cumprimentavam na porta com grande cortesia e respeitosamente a acompanhavam ao estúdio do porão. Lá ela ouvia com óbvia afeição e atenção, fazia que sim com a cabeça e murmurava, e, olhando para cima com os olhos quase perdidos nas rugas de seu rosto redondo, ela desenhava em um caderninho de rascunhos em seu posto de observação, uma cadeira acolchoada trazida do gabinete de Monsieur especialmente para ela. Ao final da noite, o próprio Decroux ou um ancien élève de confiança a acompanhava ao ponto de táxi mais próximo. Certa vez Monsieur me explicou que ela era filha de um diplomata, uma aristocrata e amiga de longa data. Leonard Pitt, a quem foi dada a incumbência de pendurar a cobertura de couro estofado nas paredes do estúdio de Monsieur, contou-me que havia sido Madame de Billy quem pagou por ela.

Em retrospecto, já que Decroux não convivia com mulheres que usavam muitas joias, eu penso que devem ter sido as 
pérolas de Madame de Billy que ele tinha em mente quando nos dizia que se nós mostrássemos a ele um colar de batatas (uma peça longa e mal feita) e pedíssemos que ele imaginasse um colar de pérolas, isso seria impossível, mas que se nós o presenteássemos com uma pérola (uma figura de improvisação curta e belamente executada) e pedíssemos que ele imaginasse um colar inteiro, ele seria capaz. A metáfora da pérola era importante também de outro modo, pois Decroux deleitava-se com a maneira como as pérolas eram feitas - de coisas pequenas, afiadas e difíceis que entram na existência do artista e precisam ser revestidas, pouco a pouco, com as secreções luminosas da técnica. Sem precisar forçar demais a imaginação, é possível comparar o porão azul com uma piscina na qual artistas-ostras produziam pérolas cultivadas, transformando as irritações e pesares da vida em joias valiosas e altamente desejáveis. Sob a tutela do mestre cultivador de ostras, que acreditava na técnica e no método tanto quanto na beleza da inspiração, nós fomos ensinados que: "A paciência é uma longa paixão".

Ao final das improvisações, depois que Madame de Billy havia achado seu táxi e a maioria dos estudantes havia se dirigido à estação de metrô ou a um café nas redondezas para celebrar o sucesso, afogar as mágoas ou debater as questões que Decroux havia levantado, a pequena casa nos fundos do jardim do número 85, da avenida Edouard Vaillant retomava sua quietude. Madame Decroux preparava o jantar enquanto Decroux ia para o seu estúdio para conversar com Mark Piper ${ }^{7}$, saboreando um copo ou dois de cerveja escura (la faiblesse) sobre o grand a das palavras inglesas.

Às vezes, nesse momento da noite, se ela já não havia vindo mais cedo naquele dia, uma vizinha de olhos reumosos, Madame Hiturelde (esposa do motorista de ônibus basco que, às vezes, filmava partes do trabalho de Decroux com sua câmera Super-8), chegava com seu cão sarnento embaixo do braço. Os gritos agudos de Madame Decroux dizendo "Oh meu docinho" alertavam Monsieur, que vinha rapidamente de seu estúdio, cheio de gentil solicitação encoberta por movimentos ágeis e eficientes. Ele puxava rapidamente a lata de açúcar 
da prateleira, colocava um cubo entre os dentes e, enquanto Madame Hiturelde empurrava a criaturinha agitada para a frente, o cachorro, bem treinado no ritual, lambia os lábios de Monsieur, removendo o açúcar. Por um breve momento os seus olhos úmidos e brilhantes se encontravam com amor mútuo e sem pruridos.

Qualquer estudante que ainda estivesse presente e que visse esse estranho ritual ao sair ficava chocado com a sua propriedade; um anarquista entretendo um monárquico, um marxista enaltecendo Deus - essas incongruências tornavamse perfeitamente apropriadas em uma casinha com jardim em Boulogne Billancourt, periferia de Paris. Ao saborear sua deliciosa ambiguidade - a inevitabilidade daquelas lições de metáforas confusas e seu contexto improvável - aquele estudante cansado, perplexo, estaria logo no metrô dirigindo-se para um quartinho no sétimo andar em um prédio sem elevador (nem aquecimento ou água), um jantar rápido de pão e queijo sentado na beirada da cama estreita, seguido de um instantâneo e profundo sono de boas-vindas, cheio de sonhos com a sublimidade e grandeza da arte, e olhos e pérolas e luzes mergulhadas em uma piscina azul. 


\section{Notas}

${ }^{1}$ Publicado originalmente em inglês em Mime Journal. Clarmont, EUA, Pomona College, 1995, p. 82-113.

${ }^{2}$ Leonard Pitt contou-me que ele recorda a primeira dessas aulas de sexta-feira à noite, aproximadamente em 1963.

${ }^{3}$ As traduções seguintes são dessas gravações.

${ }^{4}$ Entrevista com Madame M. H. Dasté em 16 de novembro de 1980, páginas 1541 e 1542 da tese de doutorado de Richard Canis.

${ }^{5}$ Decroux falou isso sobre Delsarte na sua aula de 8 de fevereiro de 1974, e, na próxima respiração e de modo perfeitamente decroviano, disse que talvez estivesse julgando Delsarte de modo injusto, e que ele talvez tivesse algo a dizer.

${ }^{6}$ Veja meu artigo "The Mask as Shamanic Tool in the Theatre Training of Jacques Copeau" em Mime Journal. 1995. Incorporated Knowledge. NR.; uma versão em língua portuguesa desse texto foi publicado na Revista da FUNDARTE, Montenegro, n. 4, p. 04-15, jul./dez. 2002.

${ }^{7}$ A tarefa de Mark era a de trazer quatro palavras inglesas que usavam o $a$ aberto para cada encontro pós-classe. Essas palavras serviam como ajuda para Decroux, que suspeitava que as estações de rádio e os canais de televisão franceses estivessem mudando a pronúncia das palavras francesas para os menos elegantes e decadentes as fechados. 


\section{Referências}

LEABHART, Thomas. Friday Night Pearls of Wisdom. Mime Journal, Words on Decroux 2, Clarmont, Pomona College, p. 82-113, 1995.

LEABHART, Thomas. A Máscara como Ferramenta Xamanística no Treinamento Teatral de Jacques Copeau. Revista da FUNDARTE, Montenegro, n. 4, p. 04-15, jul./dez. 2002.

Thomas Leabhart é mímico, ator e diretor de teatro. Foi aluno e assistente de Etienne Decroux entre 1968 e 1972. Atualmente é professor e artista residente no Departamento de Teatro e Dança no Pomona College na Califórnia, EUA. É membro da ISTA (International School of Theatre Anthropology). É editor chefe do Mime Journal.

E-mail: TGL04747@pomona.edu

Traduzido por Martin Heuser e revisado por Gilberto Icle.

Texto Convidado 